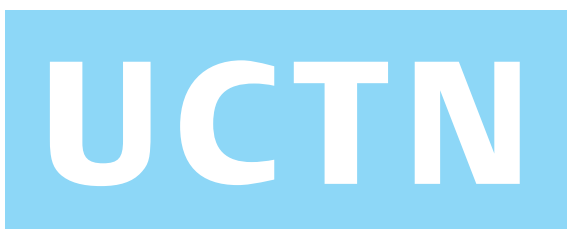

\title{
Ascending venous thrombosis from the middle hepatic vein to the left pulmonary artery as a complication of endoscopic Histoacryl sealing of a bile leak after blunt liver injury
}

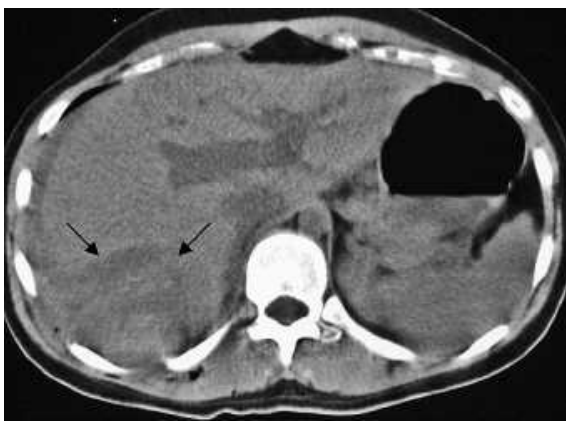

Figure 1 Computed tomographic scan performed on the day of the injury. The arrows show the rupture in liver segments VI and VII.

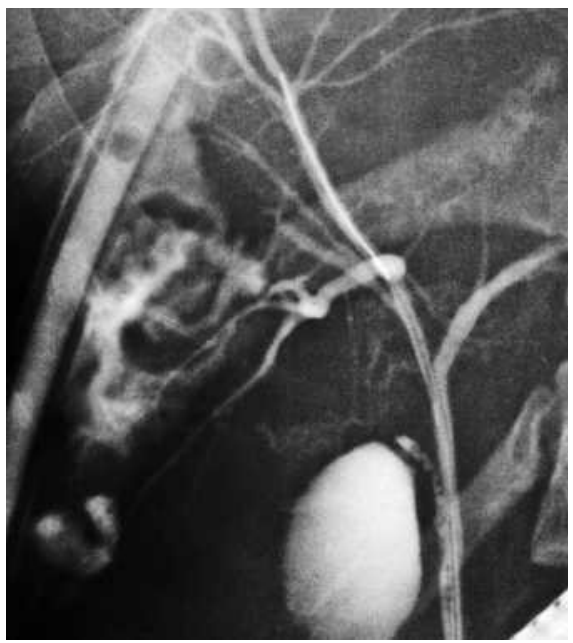

Figure 2 Cholangiogram showing bile leak from posterior branch of the right hepatic bile duct, which persisted for more than 3 weeks.

Biliary leaks can be effectively closed by endoscopic application of N-butyl-2-cyanoacrylate (Histoacryl) [1]. We describe here a young woman who developed a thrombus of the middle hepatic vein, which ascended to the right atrium, after sealing of a bile leak that had developed following blunt liver injury. The 21-yearold woman was injured as a result of a fall from a second-floor level. Computed tomography revealed that liver segments VI and VII were ruptured (Figure $\mathbf{1}$ ) and both segments were found to be avulsed at the time of surgery.

From day 7 after the injury, the patient developed a persistent leak of $100-200 \mathrm{ml}$ of

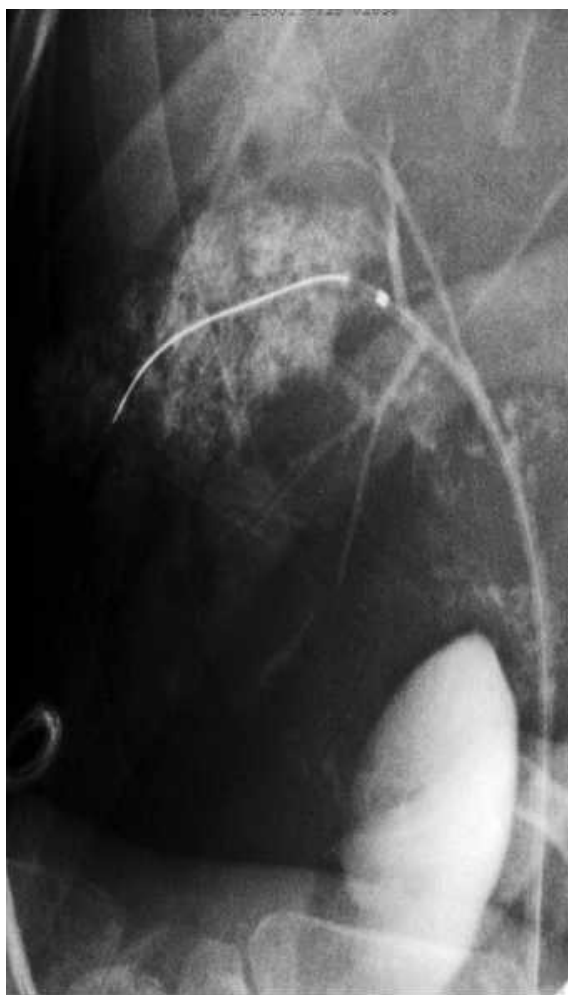

Figure 3 The catheter was positioned precisely at the site of the leak, and $2 \mathrm{ml}$ of a mixture of N-butyl-2-cyanoacrylate (Histoacryl) and Lipiodol ( $1 \mathrm{ml}$ of each) was injected.

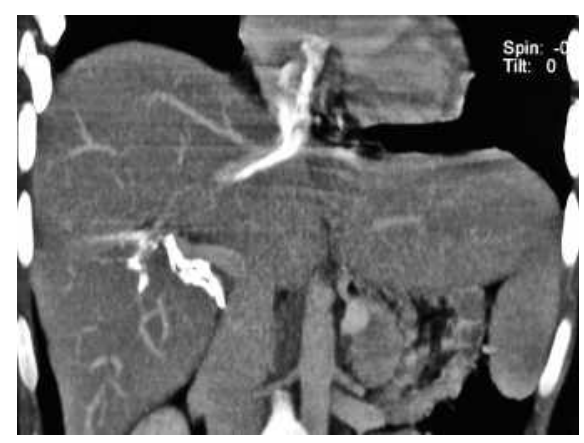

Figure 4 Embolizing material can be seen in the middle hepatic vein and the inferior vena cava.

bile per day. Sphincterotomy and endoscopic retrograde cholangiography (ERC) were performed 3 weeks later, revealing a bile leak from the posterior branch of the right hepatic bile duct (Figure 2). Histoacryl, diluted with the oily contrast agent Lipiodol, was used to seal the leak (Figure 3). This stopped the bile leakage. The

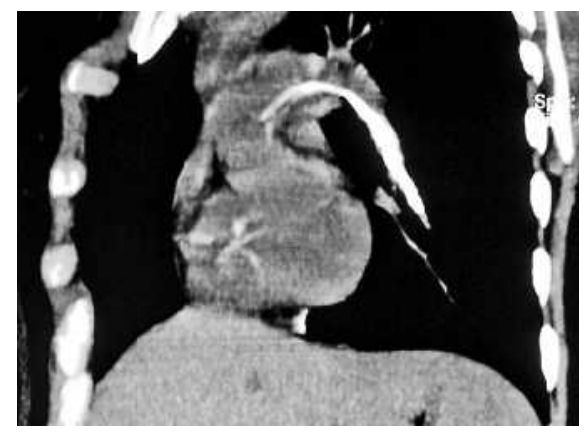

Figure 5 Embolizing material in the left pulmonary artery.

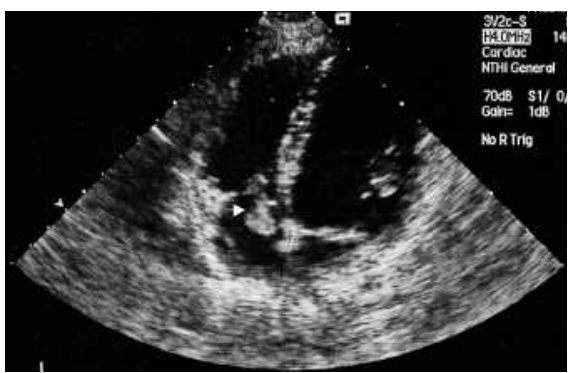

Figure 6 Serial echoardiograms all showed thrombus in the right atrium (arrow), which was causing tricuspid insufficiency. From the first echocardiogram to surgery the thrombus remained $4-4.5 \mathrm{~cm}$ in size.

patient was discharged home, but was readmitted 3 days later because she had developed a fever with body temperatures of up to $39^{\circ} \mathrm{C}$. An abscess in the right hemiliver was discovered on ultrasound examination. Her condition failed to improve despite antibiotic therapy, and a computed tomographic scan confirmed that she had a liver abscess, and also that there was a trace of Histoacryl material ascending from the middle hepatic vein (Figure 4 ) to the left pulmonary artery (Figure $\mathbf{5}$ ). A series of echocardiograms showed an iatrogenic thrombus in the right artium (Figure 6). We decided to remove the thrombus surgically, because it was causing tricuspid insufficiency and was considered likely to cause a fatal pulmonary embolism. The postoperative course was uneventful and the patient has now been symptom-free for 12 months.

DOI: $10.1055 / \mathrm{s}-2006-944598$ 
The majority of biliary leaks can be managed by endoscopic sphincterotomy and stent placement [1]. Endoscopic injection of Histoacryl is another approach, one which offers closure of persistent bile leaks. In one series of patients with biliary leaks that were sealed this way, treatment was successful in 7/9 cases [2]. We report a serious complication of this treatment, however, though one which was managed successfully in this case. Most probably, the hepatic venous system was injured in this patient and the injected Histoacryl traveled from the middle hepatic vein to the left pulmonary artery.

Endoscopy_UCTN_Code_CPL_1AH_2AG
A. Tomazic ${ }^{1}$, V. Mlinaric ${ }^{2}$, A. Pleskovic ${ }^{1}$

${ }^{1}$ Department of Abdominal Surgery, University Medical Centre Ljubljana, Ljubljana, Slovenia

2 Department of Gastroenterology, University Medical Centre Ljubljana, Ljubljana, Slovenia.

\section{References}

${ }^{1}$ Ryan ME, Geenen JE, Lehman GA et al. Endoscopic intervention for biliary leaks after laparoscopic cholecystectomy: a multicenter review. Gastrointest Endosc 1998; 47: 261-266

${ }^{2}$ Seewald S, Groth S, Sriram PV et al. Endoscopic treatment of biliary leakage with nbutyl-2 cyanoacrylate. Gastrointest Endosc 2002; 56: 916-919
Corresponding author

\section{A. Tomazic, M.D.}

Department of Abdominal Surgery University Medical Centre Ljubljana Zaloska cesta 7 1000 Ljubljana Slovenia

Fax: +386-1-522-2209

E-mail: ales.tomazic@kclj.si 